\title{
O papel dos professores das crianças em tratamento de saúde e das brinquedotecas
}

\section{hospitalares: diferentes desafios}

\author{
The role of teachers, children in health care and in hospital toys: different challenges \\ El papel de los profesores, de los niños en el tratamiento de la salud y de los juguetes hospitalarios: \\ diferentes desafíos
}

Recebido: 22/01/2022 | Revisado: 26/01/2022 | Aceito: 28/01/2022 | Publicado: 29/01/2022

\author{
Joelma Fátima Castro \\ ORCID: https://orcid.org/0000-0001-8948-7406 \\ Universidade Estadual de Maringá, Brasil \\ E-mail: castrojoelmaf@gmail.com \\ Ercília Maria Angeli Teixeira de Paula \\ ORCID: https://orcid.org/0000-0002-8619-7558 \\ Universidade Estadual de Maringá, Brasil \\ E-mail: erciliaangeli@yahoo.com.br
}

\begin{abstract}
Resumo
Este artigo tem como objetivo apresentar o papel do professor para a garantia do direito à educação às crianças em tratamento de saúde, além de discutir a importância da brinquedoteca hospitalar para a garantia do direito ao brincar e à promoção da cultura nesse contexto, considerando os desafios dessas ações em diferentes tempos. Os trabalhos de professores no atendimento pedagógico hospitalar, domiciliar e em casas de apoio para crianças enfermas, e os brinquedistas que atuam nas brinquedotecas hospitalares, existem há muito tempo no Brasil, com legislações específicas. Muitas crianças durante as fases de internação hospitalar ou de tratamento da doença, têm tido os seus processos de escolarização interrompidos devido à ausência de políticas públicas efetivas para essa área e um desconhecimento de seus direitos. A maioria da população, todavia, ainda desconhece esse direito à educação, ao lúdico, aos professores e brinquedistas. É preciso, portanto, discutir essas questões, para que os desafios, principalmente quanto ao reconhecimento desse trabalho, sejam superados.
\end{abstract}

Palavras-chave: Criança; Educação; Professor; Brinquedoteca.

\begin{abstract}
This article aims to present the role of the teacher in guaranteeing the right to education to children in health treatment, in addition to discussing the importance of the hospital toy library to guarantee the right to play and to promote culture in this context, considering the challenges of these actions in different times. The work of teachers in hospital pedagogical care, at home and in support homes for sick children, and the toys that work in hospital toys, have existed for a long time in Brazil, with specific legislation. Many children during the stages of hospitalization or treatment of the disease, have had their schooling processes interrupted due to the absence of effective public policies for this area and an ignorance of their rights. The majority of the population, however, is still unaware of this right to education, to play, to teachers and jokers. It is necessary, therefore, to discuss these issues, so that the challenges, especially regarding the recognition of this work, are overcome.
\end{abstract}

Keywords: Child; Education; Teacher; Plaything.

\section{Resumen}

Este artículo tiene como objetivo presentar el papel del profesor para la garantía del derecho a la educación a los niños en tratamiento de salud, además de discutir la importancia de la brinquedoteca hospitalaria para la garantía del derecho al jugar y a la promoción de la cultura en ese contexto, considerando los desafíos de esas acciones en diferentes tiempos. Los trabajos de profesores en la atención pedagógica hospitalaria, domiciliaria y en casas de apoyo para niños enfermos, y los brinquedistas que actúan en las juguquedotecas hospitalarias, existen desde hace mucho tiempo en Brasil, con legislaciones específicas. Muchos niños durante las fases de internación hospitalaria o de tratamiento de la enfermedad, han tenido sus procesos de escolarización interrumpidos debido a la ausencia de políticas públicas efectivas para esa área y un desconocimiento de sus derechos. La mayoría de la población, sin embargo, aún desconoce ese derecho a la educación, al lúdico, a los profesores y brinquedistas. Es necessário, por tanto, discutir estas cuestiones, para que los desafíos, principalmente en cuanto al reconocimiento de ese trabajo, sean superados.

Palabras clave: Niño; Educación; Maestro; Jugueteoteca. 


\section{Introdução}

Atualmente no Brasil, os professores de diferentes regiões têm atuado de forma a garantir o direito à educação e ao lúdico para crianças hospitalizadas ou em atendimento domiciliar e para aqueles que precisam ficar em Organizações Não Governamentais (ONGS). Este atendimento ainda não é conhecido por muitos, porém ele acontece em nosso país há mais de setenta anos sendo a primeira classe hospitalar registrada no Hospital de Jesus no Rio de Janeiro em 1950, segundo Fonseca (1999).

Os trabalhos dos professores com crianças e a manutenção de brinquedotecas hospitalares nesses espaços que englobam as relações entre educação e saúde são desafiadores, pois exigem cuidados específicos com relação aos aspectos afetivos, sociais e adaptações curriculares para os estudantes, bem como o cuidado com a limpeza dos brinquedos e materiais pedagógicos para evitar contaminações.

A higienização dos materiais, são cuidados que há muito tempo já são realizados por profissionais da saúde, por professores que atuam em hospitais e por profissionais como os brinquedistas hospitalares. Os trabalhos interdisciplinares e multidisciplinar são inestimáveis para a atenção integral das crianças em tratamento. Nesse sentido Lopes e Paula (2012, p. 165) ressaltam que "Os profissionais de saúde entendem atualmente que a hospitalização para a criança não significa apenas tratar sua enfermidade. As crianças precisam ter suas necessidades vitais realizadas, assim como seus sonhos e projetos atendidos".

Compreendemos que a saúde e a educação se imbricam ao buscar sanar as necessidades das crianças que se encontram internadas. Fonseca (2015), aponta que um dos papéis dos hospitais e dos profissionais da saúde é compreender que a criança, hospitalizada devido ao tratamento de saúde, deve prosseguir em seus estudos e os professores terem essa consciência de forma a garantir o acesso do estudante hospitalizado aos processos de aprendizagem. Para isto é preciso elaborar estratégias didáticas efetivas educacionais facilitando o retorno das crianças para as escolas regulares de origem reduzindo a defasagem de aprendizagem.

Mediante o exposto, este artigo tem como objetivo apresentar o papel do professor na garantia do direito à educação para criança em tratamento de saúde e dialogar sobre a importância da brinquedoteca hospitalar para resguardar o direito do brincar e a cultura e os desafios destes trabalhos em diferentes tempos.

\section{Metodologia}

Pensando no objetivo proposto neste artigo, optamos pela pesquisa com abordagem qualitativa, tendo como procedimento a pesquisa bibliográfica.

Com relação a abordagem qualitativa, fundamentado nas palavras de Bogdan e Biklen (1994, p. 50). temos que "Os investigadores que fazem uso deste tipo de abordagem estão interessados no modo como diferentes pessoas dão sentidos às suas vidas", Creswell (2010, p. 26) complementa essa ideia ao descrever que "A pesquisa qualitativa é um meio para explorar e para entender o significado que os indivíduos ou os grupos atribuem a um problema social ou humano".

Referente à pesquisa bibliográfica, Gil (2002) nos aponta que este tipo de estudo é realizado a partir de materiais já elaborados, como artigos e livros, permitindo ao pesquisador explorar um número maior de fontes. Medeiros (2000) nessa mesma lógica destaca que:

A pesquisa bibliográfica é caracterizada pela utilização de fontes secundárias, ou seja, pela identificação e análises dos dados escritos em livros, artigos de revistas, dentre outros. Sua finalidade é colocar o investigador em contato com que já se produzia a respeito do seu tema de pesquisa (Medeiros, 2000, p. 40). 
Diante do exposto este trabalho foi elaborado por meio de levantamento de documentos, livros e artigos disponíveis nas plataformas digitais: Google acadêmico, Biblioteca Digital Brasileira de Teses e Dissertações (BDTTD) e no Portal da Capes, tendo como palavras-chave: "educação hospitalar", "brinquedoteca", "professor" e "atendimento domiciliar".

Este trabalho está dividido em seções, primeiramente serão apresentados estudos que abordam o papel dos professores na continuidade da escolarização de crianças hospitalizados, posteriormente o artigo traz as legislações que garantem o direito a educação para estas pessoas. Em um terceiro momento será apresentado a importância da brinquedoteca nos hospitais e por último as considerações deste estudo.

\section{O Trabalho do Professor que Atende Crianças em Tratamento de Saúde}

De acordo com Paula (2005) o trabalho dos professores nos hospitais iniciou na França em 1920, na Espanha, as escolas surgiram em de meados de 1980 e, em Portugal nos anos de 2000, por meio da Carta da Criança Hospitalizada (2000) que teve como inspiração a Carta Europeia da Criança Hospitalizada, aprovada em 1986 pelo parlamento europeu.

Fonseca em 1999 realizou uma pesquisa intitulada "Atendimento pedagógico-educacional para crianças e jovens hospitalizados: realidade nacional" encomendada pelo Instituto Nacional de Estudos e Pesquisas Educacionais. Neste estudo Fonseca retratou a realidade dos professores e alunos em tratamento de saúde em nosso país, sendo que os dados levantados pela autora com as Secretarias Estaduais e Municipais de Educação. Apontaram que naquele período "[...] 80 professores atuando nas classes hospitalares e que atendem a uma média de mais de 1.500 crianças/mês na faixa etária de 0 a 15 anos de idade" (Fonseca, 1999, p.7).

Seguindo nesse viés a pesquisadora Fonseca $(1999$, p. 12) aponta dados sobre a formação destes professores que atuavam nas classes hospitalares "A formação universitária ou de pós-graduação comporta 63\% (n=37) dos professores nas classes hospitalares, representando uma elevada qualificação formal entre aqueles que exercem a docência nestas classes". Logo, a formação dos professores que trabalhavam nas classes hospitalares era diferenciada dos demais.

Além disso, temos que de 1990 até os dias atuais houve muitas mudanças, dentre elas podemos citar que o número de professores que atuam com os alunos hospitalizados é maior, porém não existem dados oficiais atuais do Ministério da Educação sobre o atendimento a essas crianças, quantas são atendidas e qual a formação dos docentes.

Os professores que atuam com as crianças nos hospitais, ou em atendimento pedagógico domiciliar ou em Organizações Não Governamentais, por exemplo, as Casas de Acolhida, que recebem as crianças em tratamento de saúde, juntamente com seus familiares que precisam se deslocar de suas cidades para outros municípios para realizarem o tratamento, eles têm buscado transformar a realidade educacional dessas crianças, de forma a garantir o direito a continuidade da educação e a vivência da infância, promovendo, atividades lúdicas e culturais, além de criar espaços que possibilitem a aprendizagem e que seja acolhedor tanto para criança como para os familiares.

O professor ao optar trabalhar com crianças em tratamento de saúde enfrenta diversos desafios, iniciando pela elaboração dos planos de atividade, o acompanhamento de processo de escolarização em conjunto com as escolas desses alunos, devido as variações ligadas ao ensino e das condições dos tratamentos em que variam podendo ser longos ou mais curtos, causando uma ruptura na vida habitual das crianças, considerando também que alguns tratamentos exigem delas constantes idas e vindas a hospitais.

Algumas crianças devido a patologia permanecem por um longo período afastadas da escola, longe dos colegas, de seus familiares e lares, sendo este período do tratamento muito marcante nas suas vidas e de sua família, alterando suas rotinas. É preciso enfatizar que o professor deve considerar as múltiplas histórias de vida e situações de aprendizado que estas crianças possuem. 
O Ministério da Educação (Brasil, 2002) por meio da Secretaria da Educação Especial (SEESP) para detalhar os diferentes tipos de atendimento, fomentou o documento que contém as estratégias e orientações para a promoção de atendimento pedagógico em espaços hospitalares e domiciliares, denominado "Classe Hospitalar e Atendimento pedagógico Domiciliar: estratégias e orientações", sendo definido a Classe hospitalar:

Denomina-se classe hospitalar o atendimento pedagógico-educacional que ocorre em ambientes de tratamento de saúde, seja na circunstância de internação, como tradicionalmente conhecida, seja na circunstância do atendimento em hospital-dia e hospital-semana ou em serviços de atenção integral à saúde mental (Brasil, 2002, p. 13).

$\mathrm{O}$ atendimento pedagógico realizado nos hospitais é organizado de maneira que a criança possa prosseguir os seus estudos enquanto permanecer internada e, ao receber alta, retorne à escola de origem se integrando à comunidade escolar ou caso necessário prossiga os estudos de forma domiciliar.

O trabalho dos professores com crianças que estão afastadas das escolas regulares e não estão internadas é denominado atendimento pedagógico domiciliar:

Atendimento pedagógico domiciliar é o atendimento educacional que ocorre em ambiente domiciliar, decorrente de problema de saúde que impossibilite o educando de frequentar a escola ou esteja ele em casas de passagem, casas de apoio, casas-lar e/ou outras estruturas de apoio da sociedade (Brasil, 2002, p. 13).

Seguindo, o documento traz:

O alunado do atendimento pedagógico domiciliar compõe-se por aqueles alunos matriculados nos sistemas de ensino, cuja condição clínica ou exigência de atenção à saúde, considerados os aspectos psicossociais, interfiram na permanência escolar ou nas condições do conhecimento, impedindo temporariamente a frequência escolar (Brasil, 2002, p. 16).

Á luz das palavras de Oliveira et al. (2016) o atendimento educacional domiciliar acontece quando a criança está matriculada em uma escola regular, porém ela não consegue frequentar a escola regularmente devido algum motivo de doença, neste caso o professor o u responsável que trabalhe com a pedagogia hospitalar vai à casa da criança para que ela tenha acesso a educação e consiga dar continuidade em seus estudos.

Zaias (2012) relata que um dos desafios enfrentados pelos professores que trabalham com as crianças em tratamento de saúde são as dificuldades de comunicação com as escolas regulares. Segundo a autora é preciso ter uma integração entre os professores das escolas regulares com os professores das escolas hospitais e em atendimento domiciliar para dar continuidade nas atividades. Porém a realidade é outra, as crianças que precisam se afastar das escolas devido à realização de tratamento de saúde, muitas vezes acabam sendo invisibilizadas, conforme destaca Paula (2010, p. 7) "Para muitos desses professores, as condições precárias de trabalho associados ao desinteresse pela realidade dos alunos faz com que essas crianças sejam esquecidas".

Zimmermann et al (2017, p. 63) pontuam que a escola: "representa para a criança um espaço afetivo e social alegre, onde pode conquistar amizades, ser produtiva, enfim expressar-se, aprimorando-se como ser individual". No espaço escolar é que a criança por meio das ações vivenciadas vai construindo sua personalidade e ao se afastar da escola ela é privada de laços afetivos e sociais com os amigos, professores e demais pertencentes a comunidade escolar.

Em vista disso, outro desafio identificado pelos professores que atuam nesses contextos é procurar minimizar a angústia, o medo, o distanciamento do cotidiano por meio do atendimento na escola, no hospital permitindo que as crianças mesmo em processo de tratamento possam vivenciar momentos lúdicos, afetivos e de aprendizagem: 
$\mathrm{O}$ atendimento na classe hospitalar tem contribuído para reduzir a ansiedade inerente à hospitalização, minimizando a dor, o medo e a desconfiança, além de dar oportunidade à criança de continuar aprendendo os conhecimentos escolares e desvincular-se, mesmo que momentaneamente, das restrições que o tratamento hospitalar impõe (Lino, 2018, p. 39).

Estudiosos defendem que esta educação tem contribuído no atendimento a crianças em tratamento de saúde, assim:

A educação no espaço hospitalar tende a humanizar o atendimento de reabilitação da saúde hospitalizada, pois promove uma interação paciente-equipe médica-família-profissionais da educação em que é possível criar um diálogo entre os sujeitos contribuindo, no estado biopsicossocial da criança. Essa atuação da educação com a saúde tem favorecido para diminuir o período de internação, garantir os direitos da criança e do adolescente à escolarização e à saúde (Silva \& Andrade, 2013, p. 63).

Desde o nascimento o indivíduo permanece em constante desenvolvimento, além dos cuidados fisiológicos, se faz necessário os estímulos para o indivíduo se desenvolver intelectualmente e socialmente, logo é preciso que as crianças mediante a situação de vulnerabilidade a qual se encontram permaneçam inseridas em ambientes que promovam o seu desenvolvimento integral por meio do lúdico, da brincadeira e da educação.

Segundo Fonseca (1999) por menor que seja o tempo destinado ao atendimento na escola, no hospital, este é expressivo para a criança, para que ela possa isentar-se momentaneamente sobre assuntos que remetem o seu adoecimento e vivenciar novas aprendizagens, tanto para sua vida como escolar.

Em outro momento Fonseca (2015) discute a falta de infraestrutura para a realização do trabalho sendo este um aspecto desafiante para os professores nos hospitais. Para ela, a escola inserida no hospital não está no planejamento e nem na construção da maioria dos hospitais, diante dessas situações, o professor precisa se adaptar para criar condições nestes espaços para realizarem suas atividades, em alguns casos, os hospitais cedem salas, espaços que não estão sendo utilizados para que o professor adapte com materiais e recursos didáticos para a concretização das atividades. Quando necessário o professor utiliza do próprio corredor ou leito dos hospitais para realizar as atividades com as crianças, pela falta de um espaço ou condição de saúde da criança. Diante do exposto,

É preciso considerar que ter um professor no hospital nem sempre implica um processo pedagógico de qualidade. Algumas condições são imprescindíveis para que ocorra um bom trabalho e que a criança ou o adolescente se sintam livres e incluídos nas propostas pedagógicas dos professores nos hospitais (Zaias \& Paula, 2010, p. 225).

As autoras complementam que é necessário o professor ter sensibilidade desde o primeiro contato, ouvindo e conhecendo aquela criança e quem a acompanha, explicar para elas e seus responsáveis qual é o papel de uma escola no hospital, quais os objetivos, propósitos e como funciona. Escutar a criança, sua história, seus sonhos, suas aflições, respeitar o tempo de cada uma faz parte do processo para que o professor possa executar um trabalho de qualidade. Paula (2015, p. 2427) corrobora com essa discussão ao descrever "nas práticas educativas construídas pelos professores nos hospitais, existem características do currículo que se assemelham as escolas formais como: os conteúdos, as avaliações e relatórios dos alunos".

Outro desafio imposto para o professor que trabalha na escola no hospital é conhecer as patologias das crianças. Antes de iniciar as atividades com elas, é necessário o professor saber das condições de saúde de cada criança, para isto é preciso que haja interação entre o professor e o profissional da saúde, para saber quais as condições da criança para que não Fonseca (2015) aponta que os familiares ou acompanhantes se tornam parceiros nas atividades dos professores, pois relatam informações para que as práticas do professor possam se adequar à criança. Em relação a formação do professor o documento do MEC de 2002 estabelece que: 
O professor deverá ter a formação pedagógica preferencialmente em Educação Especial ou em cursos de Pedagogia ou licenciaturas, ter noções sobre as doenças e condições psicossociais vivenciadas pelos educandos e as características delas decorrentes, sejam do ponto de vista clínico, sejam do ponto de vista afetivo. Compete ao professor adequar e adaptar o ambiente às atividades e os materiais, planejar o dia-a-dia da turma, registar e avaliar o trabalho pedagógico desenvolvido (BRASIL, 2002, p. 22).

O trabalho em equipe também é um desafio nos espaços que atendem crianças em tratamento de saúde. Paula (2005) discursa que além do professor, outros profissionais de equipes multidisciplinariedades como enfermeiros, psicólogos, clowns dentre outros, também buscam ouvir os medos e incertezas contados pelas próprias crianças e familiares e procuram orientá-los diante dessas dúvidas e inquietações. Essa relação de afetividade e empatia ao se colocar no lugar do outro, ocorre por meio de ações recreativas, artísticas e culturais, práticas educativas, assistência e orientação.

As crianças têm numerosas histórias de vida, que não devem ser desconsideradas devido ao tratamento de saúde. As relações afetivas são essenciais para as crianças que se encontram hospitalizadas ou em atendimento domiciliar, pois as motivam a se expressarem sobre seus sentimentos, sonhos, medos e passam a compreender o outro, a respeitar o tempo e espaço do próximo, e começam a reconhecer que mesmo estando em tratamento de saúde, possuem direitos e deveres que devem ser respeitados.

Ao discorrermos sobre afetividade no processo de escolarização para crianças em tratamento de saúde, é preciso enfatizar a importância da relação professor-aluno. O professor ao trabalhar com crianças hospitalizadas ou em atendimento domiciliar precisa respeitar suas especificidades, compreender a história e o tempo de cada um, por meio de uma relação de cumplicidade, para compreender essa importância temos:

É sabido que os professores não existem sem os alunos. No hospital, o trabalho pedagógico do professor não somente ressignifica a vida dos alunos, mas também dos professores que se vem fortalecidos afetivo e profissionalmente pelas experiencias com as crianças hospitalizadas, as quais contribuem para transformar as práticas e histórias de vida dos professores (Paula, 2005, p. 50).

Nas últimas décadas as pesquisas acadêmicas sobre o trabalho de professores com crianças em tratamento de saúde tiveram um aumento significativo, porém ainda é preciso ampliar os esforços na pesquisa e a garantia do direito a educação, cultura e ludicidade. Desde meados de 1980 existem legislações que definem esse direito a educação e ao lúdico para todas as crianças, porém para as crianças em tratamento de saúde no Brasil, o cumprimento deste direito, a contratação de professores para atuarem e a valorização deste trabalho é outro desafio a ser superado.

\section{O Direito a Educação para Crianças em Tratamento de Saúde}

$\mathrm{O}$ atendimento educacional para as crianças em tratamento de saúde não pode ser considerado apenas como uma maneira de amenizar o sofrimento da criança, mas como uma forma de garantir o direito à educação, no qual está estabelecido na Constituição Brasileira de 1988 "A educação, direito de todos e dever do Estado e da família e será promovida e incentivada com a colaboração da sociedade" (Brasil, 1988, p. 123).

A preocupação com o bem-estar, o desenvolvimento e os direitos das crianças e adolescentes, vai para além da família ou da escola, mas de toda a sociedade, assim o Conselho Nacional dos Direitos da Criança e do Adolescente (CONANDA) aprovou o texto proveniente da Sociedade Brasileira de pediatria que estabeleceu: A declaração dos direitos da criança e do adolescente hospitalizado, Resolução n41 de 13 de outubro de 1995, destacamos: "Direito a desfrutar de alguma forma de recreação, programas de educação para a saúde, acompanhamento do currículo escolar, durante sua permanência hospitalar" (1995, p. 1). 
Em 2018, a Lei 13.716 de 2018 (Brasil, 2018) alterou a Lei de Diretrizes e Bases da Educação Nacional, Lei № 9.394 de 20 de dezembro de 1996 (Brasil, 1996). Nesta lei, na seção III, na parte do Direito à Educação e do Dever de Educar foi incluído o Artigo 4 que fala sobre a garantia do direito à educação para os alunos da Educação Básica que precisam de tratamento de saúde:

Art. 4º-A. É assegurado atendimento educacional, durante o período de internação, ao aluno da educação básica internado para tratamento de saúde em regime hospitalar ou domiciliar por tempo prolongado, conforme dispuser o Poder Público em regulamento, na esfera de sua competência federativa. (Incluído pela Lei $\mathrm{n}^{\circ}$ 13.716, de 2018) (Brasil, 2018, p. 1).

É evidente que as crianças, mesmo em tratamento de saúde, têm o direito a continuidade dos seus processos de escolarização. Logo a educação e a saúde devem andar juntas e buscar contribuir para o desenvolvimento da criança.

O atendimento pedagógico-educacional em ambientes hospitalares deve ser considerado, portanto, uma interrelação de duas importantes áreas, a saúde e a educação, que dialogam para promover o desenvolvimento integral da pessoa que está buscando o tratamento de saúde, visando ao seu direito e à sua qualidade de vida, buscando resgatar, acima de tudo, aspectos humanos além dos cuidados técnicos e científicos (Santana, 2012, p. 30).

Menezes (2010, p. 16) corrobora ao descrever que "a Pedagogia Hospitalar pode contribuir para reforçar a autoestima, conferindo ao educando internado a possibilidade de contribuir para a continuidade de seu desenvolvimento, bem como lhe restituir um espaço de convivência social do qual é inesperadamente afastado".

Como descrito o Brasil possui legislações que visam garantir o direito à educação a todos. Porém ainda estamos caminhando para que essas leis sejam concretizadas. É preciso considerar que, na ausência destes atendimentos de educação e ludicidade, existem Projetos de Extensão das Universidades, com estudantes, professores e coordenadores dos cursos de Pedagogia e licenciaturas que trabalham com a educação de forma lúdica com essas crianças. Essas práticas lúdicas, educativas e culturais são diferentes das práticas dos professores que atuam cotidianamente no atendimento hospitalar, domiciliar ou Ongs.

A promoção da ludicidade para as crianças em tratamento de saúde, também encontra desafios na sua implantação. Para tanto discutiremos a seguir questões relativas sobre a brinquedoteca hospitalar no Brasil.

\section{A Brinquedoteca Hospitalar}

Em meados de 1950 surgiu a brinquedoteca hospitalar, após discussões sobre a importância do brincar, sendo ela um espaço com jogos educativos, livros e brinquedos, tendo como propósito estimular as crianças, adolescentes e familiares a brincarem no sentido mais amplo plausível, podendo a brincadeira ser realizada no próprio leito ou em espaços físicos destinados as atividades (Silva \& Andrade, 2013, p. 72).

Costa et al. (2014) discorrem que a brinquedoteca hospitalar no Brasil foi criada com base na visão de estudiosos que consideravam a eficácia da brincadeira em contribuir para o crescimento e desenvolvimento saudável das crianças, mesmo estando hospitalizadas, seu propósito era destinar um espaço para as crianças por meio das brincadeiras expressarem seus sentimentos diante da permanência no hospital.

Em defesa da inclusão do brinquedo, a importância das brinquedotecas em espaços hospitalares como parte da assistência e da terapêutica, teve seu reconhecimento em 2005, conforme prevê a lei Federal 11. 104/05 (Brasil, 2005). A lei que garantiu e assegurou a implantação de brinquedotecas nos hospitais foi defendida pela deputada Luiza Erundina, na época vinculada ao Partido da Socialista Brasileiro (PSB-SP). 
A lei 11. 104/05, de 21 de março de 2005 sofreu várias críticas a respeito da obrigatoriedade de brinquedotecas nas unidades de saúde por não abordar sobre a contratação de profissionais de educação nos hospitais. Assim, diversas situações que poderiam ser exploradas neste ambiente, ficavam limitadas, pois em alguns hospitais, as brinquedotecas não contavam com profissionais especializados para os cuidados necessários.

No mesmo ano esta lei sofreu alterações, conforme a Portaria $n^{\circ} 2.261$ de 23 de novembro de 2005 , uma delas diz respeito aos profissionais que que atuam nas brinquedotecas, ficando a cargo dos hospitais a escolha dos profissionais, conforme artigo $7^{\circ}$ "A qualificação e o número de membros da equipe serão determinados pelas necessidades de cada instituição, podendo funcionar com equipes de profissionais especializados, equipes de voluntários ou equipes mistas".

Enfatizando que as crianças em tratamento de saúde precisam permanecer inseridos em ambientes que promovam por meio da brincadeira, educação e lúdico o seu desenvolvimento integral. Entendemos que a brincadeira possibilita que as crianças se desenvolvam, criem laços afetivos e passem a compreender o mundo que as cercam,

O brincar de faz-de-conta, por sua vez, possibilita que as crianças reflitam sobre o mundo que as cerca com novos significados, tecer novas relações, desvincular-se dos significados imediatamente perceptíveis e materiais para atribuir-lhes novas significações, imprimir-lhes suas ideias e os conhecimentos que têm sobre si mesma, sobre as outras pessoas, sobre o mundo adulto, sobre lugares distantes e/ou conhecidos (Brasil, 1998, p. 171).

Por meio do lúdico e da brincadeira, as crianças passam a compreender o mudo de uma outra maneira, entendendo que mesmo em tratamento de saúde possuem direitos, oportunizando a elas refletirem sobre seus corpos, seus tratamentos, suas vivências, como também o direito de brincar, estudar e sobretudo o direito de serem respeitadas, partindo dos anseios postos por eles e seus familiares.

Ao falarmos sobre a brincadeira para crianças em tratamento de saúde, não consideramos somente esses indivíduos, mas todas as pessoas que estão inseridas na sua realidade. Em sua maioria, os familiares são muito próximos e presentes nas atividades, nos projetos voltados a eles, como no tratamento. As atividades desenvolvidas nas brinquedotecas hospitalares são meios de estreitar as relações entre a criança e os familiares e oportunizar tranquilidade e afetividade, não apenas para as crianças, mas para seus pais ou responsáveis. Mas são necessários espaços amplos que garantam o bem-estar de todos na brinquedoteca, bem como horários de atendimento com profissionais específicos.

As brinquedotecas hospitalares rompem paradigmas de que a internação é momento de isolamento, triste e que a criança não possa interagir com a sociedade se desconectando de suas rotinas, da sua realidade, sem direito de brincar, aprender e socializar-se. Neste sentido, Paula e Foltran (2007) destacam que a brinquedoteca, além de permitir o brincar e a aproximação entre pais e filhos é considerada um espaço de formação, nas palavras de Costa et al temos a definição de brinquedoteca:

A brinquedoteca é definida como um lugar preparado para estimular a criança brincar, possibilitando o acesso a uma grande variedade de brinquedos, dentro de um ambiente especialmente lúdico e interativo, ou seja, ao mesmo tempo em que a criança brinca, socializa-se; ao mesmo tempo em que se diverte, aprende a assumir responsabilidades e a respeitar o direito dos outros. É um espaço ideal para que seja cultivada as convivências espontâneas e democráticas, calçadas no respeito mútuo e renovada pela postura criativa de seus participantes (COSTA et al., 2014, p. 207).

A brinquedoteca não pode ser considerada apenas um local com brinquedos amontoados para mera distração das crianças hospitalizadas, um dos desafios é ter um espaço específico nos hospitais com higienização e manutenção dos brinquedos. A brinquedoteca pode ser organizada com cantinho da leitura, com prateleira para jogos e brinquedos, mesa para atividades de pintura, que possibilitam interação entre as crianças que estejam passando por tratamento similares, ou 
vivenciando as mesmas patologias, aprendendo a respeitar as especificidades do outro, além de despertar o interesse por novas brincadeiras, atividades lúdicas e culturais, amenizando traumas psicológicos devido ao internamento.

Para a criança, a brinquedoteca é um lugar mágico, no qual permite, a elas por um instante, esquecerem dos momentos que estão passando devido a internação e apenas vivenciar a magia do brincar. Desfrutar da brincadeira é indispensável para o desenvolvimento da criança, pois ela, oportuniza que a criança tire o foco do tratamento e comece a se interessar por outros assuntos, como literatura, jogos, música e cultura. Sobre essa afirmação as autoras discorrem:

Através do brincar a criança expressa sua visão de si e do mundo no qual vive, reproduz e recria comportamentos culturais. Ao brincar, o foco não está mais na doença e no tratamento, mas no lúdico e em todo o universo de possibilidades que a ação de brincar convida a criança participar e compartilhar estas ações com amigos (Lopes \& Paula, 2012, p. 170).

Ao brincar as crianças tendem a reproduzir sua relação com o mundo, principalmente com o outro, aqueles que possuem uma maior interação, é preciso destacar que nem todas as crianças têm acesso a brinquedotecas devido a patologia não poderem se deslocar dos leitos, nestes casos as ações são realizadas ao inverso, se levando o brinquedo até a criança em seu leito com todos os cuidados indispensáveis.

Devido à baixa imunidade das crianças, os brinquedos e jogos devem ser cuidadosamente selecionados e higienizados para evitarem a transmissão de doenças, nesse viés (Oliveira et al., 2016, p. 97) explanam que "o ideal é que os brinquedos sejam separados adequadamente; os brinquedos que vão para o leito não devem ser misturados com os da brinquedoteca; os brinquedos sujos devem ser separados em outro lugar para que possam ser limpos e lavados".

Não são apenas os brinquedos que fazem parte das brinquedotecas, os livros também pertencem ao universo infantil, ao contar história, o professor cria um ambiente de encantamento, dando espaço aos sentimentos, suspense, emoções no qual os personagens ganham vida permitindo que a criança dê asas à imaginação, deixando de ser meros ouvintes e se tornando protagonista da história. "As histórias infantis, quando bem contadas, exercem um grande fascínio nas crianças e permitem que elas sejam transportadas para um mundo de faz de conta no qual tudo pode acontecer" (Matos \& Paula, 2011, p. 7485).

Ao contarmos histórias, elas nos permitem ir além do real e nos possibilita invadirmos o mundo da imaginação no qual habitam cavalos, dragões, princesas e heroínas, permitindo o aprendizado ao mesmo tempo. Bernardinelli e Carvalho (2011, p. 455) colaboram com essa ideia ao descrever que "ouvir e ler histórias é entrar em um mundo encantador, cheio ou não de mistérios e surpresas, mas sempre muito interessante, curioso, que diverte e ensina".

Nas palavras de Coelho (2000, p. 27): “A literatura infantil é, antes de tudo, literatura; ou melhor, é arte: fenômeno de criatividade que representa o mundo, o homem, a vida, através da palavra. Funde os sonhos e a vida prática, o imaginário e o real, os ideais e sua possível/ impossível realização".

Nesse viés Vendrame (2015, p. 47) discorre que: que "a literatura é criadora de mundo, de sujeitos, e é uma ponte que nos conduz ao mundo das realizações e das trocas de vivências". Refletindo sobre o exposto podemos descrever que a literatura é o oxigênio que nos faz respirar nos dias alegres, dá colorido aos dias cinzentos e tranquiliza os momentos de aflição, logo sempre haverá uma história para contar.

A criança ao receber um atendimento mais humanizado, permite que ela veja o mudo através da literatura, conhecendo outros lugares e outros tempos, imaginando o que está no livro, o que para algumas pessoas são apenas páginas, para ela é o medicamento que ameniza suas aflições. Alves complementa ao sustentar que: "A literatura para a criança mais do que um modo de lazer e aquisição de saberes é uma forma de compreensão e reelaboração do mundo".

Esses excertos nos revelam a importância da literatura no contexto hospitalar como as autoras nos descrevem: 
Dessa forma, ao contar histórias para as crianças, em especial para as que estão em tratamento de saúde, percebe-se como a literatura infantil possibilita a expressão dos sentimentos, angústias, dores dessas crianças e contribui para a superação de algumas dificuldades, pois fortalece as crianças para vivenciarem as situações de internação e o transcorrer do tratamento (Paula \& Davina, 2018p. 97).

Em outras palavras, a literatura realizada com as crianças em tratamento de saúde é essencial pois permitem, por meio da contação de história, que elas falem dos seus sentimentos, das suas dores e alegrias, que elas se expressem.

Diante do exposto, vimos a importância dos livros infantis nas brinquedotecas hospitalares, no qual a criança pode escolher a história que ela queira ouvir em determinado momento, pois para cada momento há uma história a ser contada e de maneiras diferentes, despertando na criança a magia e a fantasia de ver em uma mesma história infinitas possibilidades.

Entendemos que a literatura, a ludicidade e o brincar devem fazer parte da vida cotidiana de todas as crianças, inclusive daquelas que se encontram em tratamento de saúde, essas práticas permitem um sorriso que pode ser considerado como cascatas ou efeito dominó, contagiando não apenas as crianças, mas familiares, amigos e profissionais da educação e da saúde, tornando o ambiente hospitalar mais leve e não sendo visto apenas como um espaço de dor e sofrimento, mas acolhedor, afetivo, de cura e de novas histórias.

\section{Considerações Finais}

Neste trabalho buscamos apresentar o papel do professor na garantia do direito a educação para crianças em tratamento de saúde e dialogar sobre a importância da brinquedoteca hospitalar para garantir o direito do brincar e da cultura neste contexto, assim como os desafios destes trabalhos.

É preciso ressaltar que mesmo com a criação de leis sobre o lúdico e a educação para crianças que se encontram em tratamento de saúde, ainda temos muito que discutir sobre esse assunto, como a estrutura destinada para a realização de atividades, as condições de trabalho e a formação dos professores que irão atuar nas escolas nos hospitais ou em atendimento educacional domiciliar.

Além destas questões mencionadas enfatizamos a importância da afetividade, do brincar, do lúdico e das relações para o desenvolvimento integral da criança, sendo na brincadeira que elas expressam suas alegrias e inquietações.

Durante o brincar, a contação de história é que as crianças esquecem suas patologias por um momento e vivenciam apenas a infância, experimentam o momento de magia que a literatura, a brincadeira e a ludicidade proporcionam a elas. Sendo a brinquedoteca hospitalar o espaço para as crianças vivenciarem estes momentos e concomitantemente criarem laços de amizade e afetividade.

Finalizamos este trabalho deixando a possibilidade de novos estudos sobre essa temática por exemplo as contribuições que a educação pode trazer para s crianças que se encontram internadas ou em atendimento domiciliar, como são realizadas as aulas nesses espaços de forma que atendam as especificidades de cada criança, dentre outras questões que podem ser abordadas, este assunto é muito amplo e ainda há muito que se dialogar.

\section{Agradecimentos}

O presente trabalho foi realizado com apoio da Coordenação de Aperfeiçoamento de Pessoal de Nível Superior Brasil (CAPES).

\section{Referências}

Alves, A. M. M., \& Grützmann, T. P. (2020). Literatura infantil no ensino da matemática: Relações presentes na formação inicial do futuro docente. Cadernos de Letras 1(38), 201-214. 
Bernardinelli, L. L., \& Carvalho, V. M. G. (2011). A importância da literatura infantil. Revista Científica do Unisalesiano, 455-460.

Bogdan, R. C.; Biklen, S. K (1994). Investigação qualitativa em educação: uma introdução à teoria e aos métodos. Porto Editora.

Brasil. (1996) Lei das Diretrizes e Bases da Educação.

Brasil (1988). [Constituição (1988)]. Constituição da República Federativa do Brasil. Supremo Tribunal Federal.

Brasil (2002). Classe hospitalar e atendimento pedagógico domiciliar: estratégias e orientações. Secretária de Educação Especial. Brasília, MEC/SEESP.

Brasil (2005) Lei no 11.104 de 21 de março de 2005. Dispõe sobre a obrigatoriedade de instalação de brinquedotecas nas unidades de saúde que ofereçam atendimento pediátrico em regime de internação. Diário Oficial [da] República Federativa do Brasil, DF.

Brasil (2018). Lei no 13.716, de 24 de setembro de 2018. Brasília. http://www.planalto.gov.br/ccivil_03/Constituicao/Emendas/Emc/emc59.htm

Brasil (1998) Referencial curricular nacional para educação infantil: conhecimentos do mundo.

Coelho, N. N. (2000). Literatura Infantil: teoria: análise: didática. Moderna.

Conselho nacional dos direitos da criança e do adolescente. (1995) Direitos da criança e do adolescente hospitalizados. Resolução $n^{\circ} 14$, de 13/10/1995. Diário Oficial da União: República Federativa do Brasil. Brasília. https://portaldeboaspraticas.iff.fiocruz.br/biblioteca/resolucao-n-41-de-13-de-outubro-de$1995 /$

Costa, S. A. F.; Ribeiro, C, A., Borba, R, I, H, \& Sanna, M, C. (2014). Brinquedoteca hospitalar no Brasil: Reconstruindo a história de sua criação e implantação (au). Hist.. enferm. Ver. Eletrônica. 5(2), 206-223.

Creswell, J. W. (2010). Projeto de pesquisa: método qualitativo, quantitativo e misto, Artmed.

Fonseca, E. S. (1999). Classe hospitalar: ação sistemática às necessidades pedagógico-educacionais de crianças e adolescentes hospitalizados. Temas sobre Desenvolvimento, 8(44), 32-37.

Fonseca, E. S. (2005). Classe hospitalar e atendimento escolar domiciliar: direito de crianças e adolescentes doentes. Revista Educação e Políticas em Debate, $4,12-28$.

Gil, A. C. (2002). Como elaborar Projetos de Pesquisa (4a ed.), Atlas

Lino, A. M. (2018). Olhares e narrativas de crianças hospitalizadas sobre a vida escolar. São Carlos: Universidade Federal de São Carlos.

Lopes, B. A., \& Paula, E. M. A. T. (2012). O significado das festas em uma brinquedoteca hospitalar: promoção da saúde, da cultura e da vivência da infância para crianças enfermas. Sociedade Brasileira de Psicologia Hospitalar. 15(1).

Matos, L. P. K., \& Paula, E. M. A. T. (2011). O papel da literatura infantil para crianças e adolescentes hospitalizados no enfrentamento dos medos infantis. In: Anais do X Congresso Nacional de Educação-EDUCERE. I Seminário Internacional de Representações Sociais, Subjetividade e Educação-SIRSSE, Curitiba, PR.

Medeiros. J. B. (2000). Redação cientifica: A prática de fichamentos, resumos e resenhas. (4a ed.), Atlas.

Menezes, C. V. A. (2010). Serviço de atendimento à rede de escolarização hospitalar: o caráter inovador na construção de uma política pública no estado do Paraná. In Serviço de atendimento à rede de escolarização hospitalar (SAREH). Cadernos temáticos, Curitiba-SEED/PR, 15-30.

Oliveira, É. F de., Silva, V. M da, \& Fantacini, R. A. F. (2016). Pedagogia hospitalar: a brinquedoteca em ambientes hospitalares. Research, Society and Development, , 88-104.

Paula, E.M.A.T., \& Foltran, E. P. Brinquedoteca hospitalar: Direito das crianças e adolescentes hospitalizados. Revista Conexão UEPG, 3(1), 1-5.

Paula, E. M. A. T. (2004). Educação, diversidade e esperança: A práxis pedagógica no contexto da escola hospitalar. Salvador: Universidade Federal da Bahia, Salvador, BA.

Paula, E. M. A. T., \& Davina, L. G. C. T. (2018). Literatura infantil para crianças enfermas: Contribuições na formação de professores. Nuances: estudos sobre Educação, 29(3), 95-107.

Paula, E. M. A. T. (2015). Escola no hospital: Espaço de articulação entre educação formal e educação não formal. http://livrozilla.com/download/390342.

Paula, E. M. A. T. (2010) Pedagogia hospitalar social: Reflexões teóricas. In: Anais do III Congresso Internacional de Pedagogia Social, São Paulo, SP.

Santana, C. (2012). Práticas de leitura em um hospital do município de Vitória/ES. Vitória: Universidade Federal do Espírito Santo.

Silva, N., \& Andrade, E. S. (2013). Pedagogia Hospitalar. Fundamentos e Práticas de humanização e cuidado. Cruz das Almas.

Vendrame, E. C. S. (2015). Da história contada ao sujeito da contação: Como me fiz contadora de história. Universidade Estadual de Maringá, Maringá, PR.

Zaias, E. (2012). Os desafios da constituição do currículo para a escola no hospital. In: Anais do Seminário de pesquisa em educação da região sul, Caxias do Sul, RS.

Zaias, E., \& Paula, E. M. A. T. (2010). A produção acadêmica sobre práticas pedagógicas em espaços hospitalares: análise de teses e dissertações. Educação Unisinos, 14(3), 222-232.

Zimmermann, A., Bonifácio, A, R., Nascimento, R, \& Kibrit, S, Z. (2017). Pedagogia hospitalar favorecendo a continuidade escolar da criança hospitalizada. Doxa: Ver. Bras. Psicol. Educ. 19(1), 62-66. 